\title{
Dr. Dietrich Hoffmann, Recipient of the 2004 Tobacco Science Research Conference Lifetime Achievement Award
}

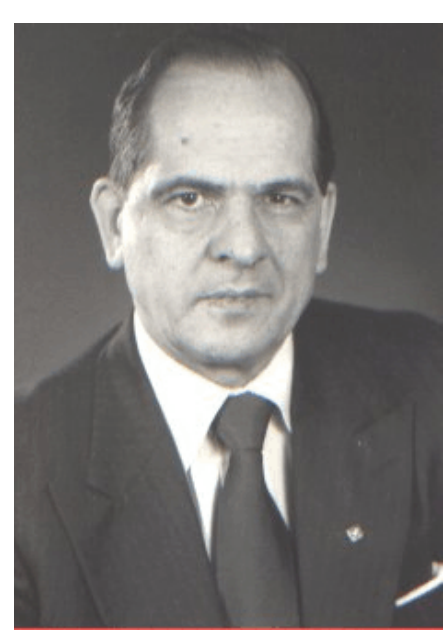

In 2003, the Policy Committee of the Tobacco Science Research Conference initiated the presentation of a Lifetime Achievement Award to a person who had contributed much over the years to the Tobacco Industry, to tobacco science, and to the Tobacco Chemists' Research Conference and the Tobacco Science Research Conference. I was greatly honored and extremely pleased to present the 2004 award to Dr. Dietrich Hoffmann on September 21,2004. The following includes an abbreviated version of his biography plus comments - many of a personal nature - that I made during the award presentation at the $58^{\text {th }}$ Tobacco Science Research Conference banquet. A more detailed version of Dr. Hoffmann's biography may be found in the Program Booklet and Abstracts for the $58^{\text {th }}$ Conference (1).

Dr. Dietrich Hoffmann received a Bachelor of Science degree in science (1952) and Master of Science degree in chemistry (1955) at Kiel University in Germany and then his doctorate in biochemistry in 1957 from the prestigious Max Planck Institute for Biochemistry in Munich. Under the direction of Nobel laureate Professor Dr. Adolf Butenandt, Dr. Hoffmann acquired his lifelong passion for the science of natural products. In 1957, Dr. Hoffmann joined Dr. Ernst L. Wynder at the Sloan-Kettering Institute in New York NY. In 1970, Dr. Wynder, Dr. Hoffmann, and many of their colleagues left the Sloan-Kettering Institute for their newly-formed American Health Foundation. Because of the nature of the research conducted there, the American Health Foundation subsequently became the Institute for Cancer Prevention, a facility that was recently closed.

In addition to his contributions to over one hundred presentations at the Tobacco Chemists' Research Conference (TCRC) and Tobacco Science Research Conference (TSRC) since 1966, Dr. Hoffmann has also published over 500 tobacco-related articles in the scientific literature, including the noteworthy 1967 book "Tobacco and tobacco smoke: Studies in experimental carcinogenesis", coauthored with Dr. Wynder.
My comments on Dr. Hoffmann on the evening of September 21, 2004 follow:

Since many of you are much younger than I, you may not know too much about Dr. Hoffmann's early career that subsequently became so auspicious. Let me take you back nearly five decades in time.

I first became aware of Dr. Dietrich Hoffmann in the late 1950s. Dr. George F Wright, Organic Chemistry Professor at the University of Toronto in Toronto, Canada and the advisor on my bachelor, master and doctoral theses, was a collaborator with Dr. Ernst L. Wynder from the early to the late 1950s. A half dozen or so of Dr. Wright's early publications on the chemical and biological properties of tobacco smoke were co-authored with Dr. Wynder (2). When their relationship ended, Dr. Hoffmann became Dr. Wynder's main tobacco smoke chemistry collaborator.

Because of my attendance at several annual American Association for Cancer Research (AACR) meetings, I learned of Dr. Hoffmann's early contributions to tobacco science from Dr. Wynder's description of the research results on the chemistry and biology of tobacco smoke at the Sloan-Kettering Institute, chemical research obviously conducted by Dr. Hoffmann. The titles of Dr. Wynder's presentations are highly indicative of Dr. Hoffmann's early contributions to tobacco science.

1959 - Wynder and Hoffmann: The role of higher polycyclic hydrocarbons in tobacco carcinogenesis (3);

1960 - Wynder and Hoffmann: Studies in tobacco carcinogenesis (4);

1961 - Wynder and Hoffmann: Biological and chemical studies of tobacco smoke condensate (5);

1962 - Wynder and Hoffmann: Studies with the gaseous and particulate phase of tobacco smoke (6);

1963 - Wynder and Hoffmann: Bioassays on the carcinogenicity of tobacco smoke condensate and air pollutants (7).

In the late 1950s, there were many in the scientific community who did not believe that UV spectral data of a tobacco smoke component identical with those of authentic benzo $[a]$ pyrene indicated its presence in tobacco smoke. Dr. Hoffmann ran into such a situation among those in the world outside the Sloan-Kettering Institute, I ran into the same situation among several of my research managers. Both of us responded to the situation in the same way. In his case, Drs. Wynder and Hoffmann reported in 1959 not only UV spectral data corresponding completely with those of authentic benzo[ $a]$ pyrene but they also described the isolation of crystalline benzo[ $a]$ pyrene from cigarette mainstream smoke during a meeting presentation (3) and in a publication (8) as follows: 
We proceeded, after paper chromatography, in getting crystalline benzo $[a]$ pyrene through the use of high vacuum sublimation and recrystallization ... The purity of this substance has been established by melting point and mixture melting point.

In studies in the 1970s and 1980s, much identification of tobacco and smoke components was accomplished by the use of a variety of spectral data. Seldom was the component actually isolated. The isolation and crystallization of benzo $[a]$ pyrene from the mainstream smoke condensate from a modest number of cigarettes represented a remarkable micro analytical feat in 1959! After the Wynder-Hoffmann 1959 publication, the presence of benzo $[a]$ pyrene in cigarette smoke was almost universally accepted, even by such a skeptic as the eminent polycyclic aromatic hydrocarbon expert Dr. Louis Fieser of Harvard University.

During the next few years from 1959 to 1963 , Dr. Hoffmann authored or co-authored some two dozen additional publications on the chemical and biological properties of tobacco smoke and of several of its newly identified components. In the following year - 1964 - the Wynder-Hoffmann 200+ page article on tobacco and smoke was published in Advances in Cancer Research (9). It was the precursor, if you will, of the Wynder-Hoffmann 1967 “bible" on tobacco and tobacco smoke (10).

I finally met Dr. Hoffmann in 1966 in Winston-Salem, North Carolina at the $20^{\text {th }}$ TCRC. That in itself is an interesting story about Dr. Hoffmann: I and several others in Winston-Salem at R.J. Reynolds Tobacco Co. R\&D and Wake Forest University Chemistry Department were responsible for putting on the Conference that year. Despite being involved in the mechanics of the Conference, I managed to audit many of the presentations on Tuesday, November 1 , the $1^{\text {st }}$ day of the Conference. I noticed that at the end of each presentation when the session chairman solicited questions from the audience, in every instance a tall gentleman stood and asked a question. It made no difference whether the presentation subject was smoke filtration, human smoking parameters, smoke composition, tobacco composition, tobacco agronomy, he had a question. I learned that the inquisitive gentleman was Dr. Dietrich Hoffmann. Later, he and I met and conversed during the afternoon coffee break. When you examine his research productivity since then, it is obvious that Dr. Hoffmann has retained his inquisitiveness to this day.

What about his participation in TCRCs and TSRCs? As I mentioned previously, Dr. Hoffmann attended his first TCRC in 1966 - the 20th - held in Winston-Salem North Carolina. That year, Dr. Hoffmann was the co-author of two presentations: One with Ms. Hiltrud Woziwodski on the identification of high molecular weight acids in tobacco and smoke (11); the other with Dr. Gunter Rathkamp on the effect of nitrate treatment of tobacco on the levels of polycyclic aromatic hydrocarbons in its smoke (12). As it happened, I chaired that Wednesday morning session which included Dr. Hoffmann's two co-authored presentations. At our Conferences from 1966 through the current one, Dr. Hoffmann has authored or co-authored more than 100 presentations, including presentations at several TCRC Symposia. That number represents two dozen more than the next in line. In our Symposium presentation at the $50^{\text {th }}$ TCRC in 1996, Dr. Charles R. Green and I commended the courage it took for Dr. Hoffmann and his Sloan-Kettering and American Health Foundation colleagues to present papers at those late 1960s and early 1970s TCRCs (13). We stated:

TCRC scientists have a long, healthy tradition in challenging each others' results or their interpretation. Criticisms based more on opinion rather than science have not survived. A special mention is owed [Dr.] Hoffmann and his colleagues from the American Health Foundation who have brought excellent science but at times controversial interpretations to the TCRC. Although they have numerous beliefs we do not share, they deserve much credit for standing amongst us.

How many Tobacco Industry R\&D personnel did likewise in the 1960 s, 1970 s, and early 1980 s by presenting the results of their tobacco or tobacco smoke research at an annual AACR conference or annual American Cancer Society meeting or the like?

What about the subject matter of his research? Dr. Hoffmann has investigated and published on most of the major categories of tobacco smoke, particularly those proposed as possible health problems. Chronologically, like many of us, he studied the polycyclic aromatic hydrocarbons (14), the aza-arenes (15), the phenols (16), the ciliastatic components (17), the $N$-nitrosamines (18), and finally of course the tobacco-specific $N$-nitrosamines (19). Within that series of major topics, there were research digressions into other smoke-related subjects such as nitric oxide (20), carbon monoxide (21), nitroparaffins (22), pesticides (23), smoke pH (24), and the like.

Reporting of nitrosamine research came rather late to the TCRC, but after the first $N$-nitrosamine presentation in 1969 , it soon became apparent that $N$-nitrosamine research had become the special province of Dr. Hoffmann and his colleagues at American Health Foundation. They authored nine of the first dozen TCRC presentations on $\mathrm{N}$-nitrosamines. Examination of the list of nearly $60 \mathrm{~N}$-nitrosamine presentations at the TCRC from 1966 to 1995 reveals that Dr. Hoffmann and his colleagues contributed more than $60 \%$ of them (13). Although that percentage has decreased somewhat in recent years because of the increased number of $N$-nitrosamine contributions from other laboratories, $\mathrm{Dr}$ Hoffmann has been the co-author of about $42 \%$ of the 95 $N$-nitrosamine papers presented at our Conference from 1969 through 2003.

When one catalogs what this gentleman has accomplished in tobacco research since the late 1950s, the statistics are incredible, one might say even awesome. Take note of this: Dr. Hoffmann has authored or co-authored nearly 600 tobacco-related articles and presentations over a period of 47 years. What does that mean? It means he averaged a contribution a month during that time period. Also, his published articles constitute over 6200 pages!

Not only are these numbers highly significant but the science delivered has usually been quite meaningful. Two interesting episodes have resulted from his efforts. Because of his numerous publications since 1986 of lists of toxicants in tobacco and tobacco smoke (25), Dr. Hoffmann was dubbed "The Author of the List" in 2002 (26). This recognition has subsequently been extrapolated in numerous Conference presentations and journal publications in which Dr. Hoffmann's list contributions were acknowledged in the title by inclusion of the term "Hoffmann analytes" or "Hoffmann-type analytes" or "Hoffmann list compounds", e.g., a TSRC presentation in 
2002, No. 29 (27), six TSRC presentations in 2003 (Nos. $14,30,44,46,47$, and 50) (28), and another presentation in 2004, No. 70 (29). In some published articles, the term "Hoffmann analytes" does not appear in the title but does appear in the headings of tables in the articles, e.g. in several recent publications by Dr. Richard R. Baker and his colleagues at BAT (30).

Ladies and gentlemen, it is not only an honor and a privilege but also a great personal pleasure for me to present the TSRC Lifetime Achievement Award for 2004 to Dr. Dietrich Hoffmann who, in my opinion, must be considered a legend in his own time. In his absence, this year's Lifetime Achievement Award will be accepted on Dr. Hoffmann's behalf by his long-time colleague Dr. Klaus Brunnemann.

\section{REFERENCES}

1. Lifetime Achievement Award: Dr. Dietrich Hoffmann; $58^{\text {th }}$ Tobacco Science Research Conference, Program Booklet and Abstracts, Vol. 58, 2004, pp. 4-5.

2. Wright, G.F: Studies with tobacco smoke condensate; in: Proc. 3rd Natl. Cancer Conf., June, 1956, JB Lippincott Company (1957) 479-484.

Wright, G.F and E.L. Wynder: Fractionation of cigarette tar; Proc. Am. Assoc. Cancer Res. 2(1) (1955) 5.

Wright, G.F and E.L. Wynder: Further chemical studies of cigarette smoke condensate; Proc. Am. Assoc. Cancer Res. 2(2) (1956) 159.

Wright, G.R. and R.J. Shephard: Carbon monoxide, nicotine and the safer cigarette; Respiration 35 (1978) 40-52.

Wynder, E.L., S. Gottlieb, and G.F Wright: A study of tobacco carcinogenesis. IV. Different tobacco types; Cancer 10 (1957) 1206-1209.

Wynder, E.L. and G.F Wright: Fractionation of cigarette tar; Proc. Am. Assoc. Cancer Res. 2(1) (1955) 55.

Wynder, E.L. and G.F Wright: Studies on the identification of carcinogens in cigarette tar; Proc. Am. Assoc. Cancer Res. 2(2) (1956) 159; A study of tobacco carcinogenesis. I. The primary fractions; Cancer 10 (1957) 255-271.

Wynder, E.L., G.F Wright, and J. Lam: A study of tobacco carcinogenesis. V. The role of pyrolysis; Proc. Am. Assoc. Cancer Res. 2(4) (1958) 357-358; Cancer 11 (1958) $1140-1148$.

Wynder, E.L., G.F Wright, and J. Lam: A study of tobacco carcinogenesis. VI. The role of precursors; Cancer 12 (1959) 1073-1078.

3. Wynder, E.L. and D. Hoffmann: The role of higher polycyclic hydrocarbons in tobacco carcinogenesis; Proc. Am. Assoc. Cancer Res. 3(1) (1959) 74. See Rodgman A, RDM, 1959, No. 41, April 20, www.rjrtdocs.com 501009779 -99792.

4. Wynder, E.L. and D. Hoffmann: Studies in tobacco carcinogenesis; Proc. Am. Assoc. Cancer Res. 3(2) (1960) 164. See Rodgman A, RDM, 1960, No. 32, April 13, see www.rjrtdocs.com $502816003-6012$.

5. Wynder, E.L. and D. Hoffmann: Biological and chemical studies of tobacco smoke condensate; Proc. Am. Assoc. Cancer Res. 3(3) (1961) 280. See Rodgman A, RDM, 1961, No. 35, April 20, www.rjrtdocs.com 504913207 -3220.

6. Wynder, E.L. and D. Hoffmann: Studies with the gaseous and particulate phase of tobacco smoke; Proc. Am. Assoc. Cancer Res. 3(4) (1962) 373. See Rodgman A, RDM, 1962, No. 41, May 15, www.rjrtdocs.com 500601317 -1328.

7. Wynder, E.L. and D. Hoffmann: Bioassays on the carcinogenicity of tobacco smoke condensate and air pollutants; Proc. Am. Assoc. Cancer Res. 4(1) (1963) 73. See
Rodgman A, RDM, 1963, No. 44, June 7, www.rjrtdocs.com $504913230-3249$.

8. Wynder, E.L. and D. Hoffmann: A study of tobacco carcinogenesis. VII. The role of higher polycyclic hydrocarbons; Cancer 12 (1959) 1079-1086.

9. Wynder, E.L. and D. Hoffmann: Experimental tobacco carcinogenesis; Adv. Cancer Res. 8 (1964) 249-453.

10. Wynder, E.L. and D. Hoffmann: Tobacco and tobacco smoke: Studies in experimental carcinogenesis. Academic Press, New York NY, 1967.

11. Woziwodski, H. and D. Hoffmann: Free higher fatty acids in tobacco and tobacco smoke; 20th Tobacco Chemists' Research Conference, Program Booklet and Abstracts, Vol. 20, Paper No. 16, 1966, pp. 19-21.

12. Rathkamp, G., D. Hoffmann, and E.L. Wynder: Experiments on the reduction of polynuclear aromatic hydrocarbons in cigarette smoke; $20^{\text {th }}$ Tobacco Chemists' Research Conference, Program Booklet and Abstracts, Vol. 20, Paper No. 19, 1966, p. 23.

13. Green, C.R. and A. Rodgman: The Tobacco Chemists' Research Conference: A half century forum for advances in analytical methodology of tobacco and its products; Recent Adv. Tob. Sci. 22 (1996) 131-304.

14. Hoffmann, D. and G. Rathkamp: [Chemical studies on tobacco smoke. XIV.] Quantitative determination of fluorenes in cigarette smoke and their formation by pyrosynthesis; Anal. Chem. 44 (1972) 899-904; Hoffmann, D., G. Rathkamp, S. Nesnov, and E.L. Wynder: Chemical studies on tobacco smoke. XVI. Alkylfluoranthenes: Determination in cigarette smoke, formation by pyrolysis, and tumor initiation activity; J. Natl. Cancer Inst. 49 (1972) 1165-1175; Hecht, S.S., W.E. Bondinell, and D. Hoffmann: [Chemical studies on tobacco smoke. XXIX.] Chrysene and methylchrysenes: Presence in tobacco smoke and carcinogenicity; J. Natl. Cancer Inst. 53 (1974) 1121-1133.

15. Hoffmann, D. and J. Rubin: Chemical studies on tobacco smoke. I. The quantitative determination of indoles in cigarette smoke; Beitr. Tabakforsch. 3 (1966) 409-414; Hoffmann, D., G. Rathkamp, and H. Woziwodzki: Chemical studies on tobacco smoke. VI. Quantitative determination of carbazoles in cigarette smoke; Beitr. Tabakforsch. 4 (1968) 253-263; Dong, M., I. Schmeltz, E. Jacobs, and D. Hoffmann: Aza-arenes in tobacco smoke; $31^{\text {st }}$ Tobacco Chemists' Research Conference, Program Booklet and Abstracts, Vol. 31, Paper No. 43, 1977, p. 22; Adams, J.D., E.J. LaVoie, A. Shigematsu, P. Owens, and D. Hoffmann: Quinoline and methylquinolines in cigarette smoke: Comparative data and the effect of filtration; J. Anal. Toxicol. 7 (1983) 293-296.

16. Hoffmann, D. and E.L. Wynder: Die quantitative Bestimmung von Phenolen in Tabakrauch; Beitr. Tabakforsch. 1 (1961) 101-106; Die Filtration von Phenolen aus Cigarettenrauch; Beitr. Tabakforsch. 2 (1963) 51-66; Filtration of phenols from cigarette smoke; J. Natl. Cancer Inst. 30 (1963) 67-84.

17. Wynder, E.L., H.E. Kaiser, D.A. Goodman, and D. Hoffmann: A method for determining ciliastatic components in cigarette smoke; Cancer 16 (1963) 1222-1225.

18. Hoffmann, D. and J. Vais: Analysis of volatile $N$-nitrosamines in unaged mainstream smoke; $25^{\text {th }}$ Tob. Chem. Res. Conf., Louisville KY (1971): Paper No. 23.

19. Hoffmann, D., S.S. Hecht, R.M. Ornaf, and E.L. Wynder: $N$ 'Nitrosonornicotine in tobacco; Science 186 (1974) 265-267; Hoffmann, D., J.D. Adams, K.D. Brunnemann, and S.S. Hecht: Assessment of tobacco-specific $N$-nitrosamines in tobacco products; Cancer Res. 39 (1979) 2505-2509; Rühl, C., J.D. Adams, and D. Hoffmann: Chemical studies on tobacco smoke. LXVI. Comparative assessment of volatile and tobacco-specific $N$-nitrosamines in the smoke of selected 
cigarettes from the U.S.A., West Germany and France; J. Anal. Toxicol. 4 (1980) 255-259; Adams, J.D., K.D. Brunnemann, and D. Hoffmann: Chemical studies on tobacco smoke. LXXV. Rapid method for the analysis of tobaccospecific $N$-nitrosamines by gas-liquid chromatography with a thermal energy analyzer; J. Chromatography 256 (1983) 347-351.

20. Adams, J.D., K.D. Brunnemann, and D. Hoffmann: Determination of nitric oxide in unaged smoke by GSC-TEA; $32^{\text {nd }}$ Tobacco Chemists' Research Conference, Program Booklet and Abstracts, Vol. 32, Paper No. 36, 1978, p. 19.

21. Brunnemann, K.D. and D. Hoffmann: Chemical studies on tobacco smoke. XXIV. A quantitative method for carbon monoxide and carbon dioxide in cigarette and cigar smoke; J. Chromat. Sci. 12 (1974) 70-75.

22. Rathkamp, G., D. Hoffmann, and E.L. Wynder: Primary and secondary nitrohydrocarbons in cigarette smoke; $21^{\text {st }}$ Tobacco Chemists' Research Conference, Program Booklet and Abstracts, Vol. 21, Paper No. 25, 1967, p. 14; Hoffmann, D. and G. Rathkamp: Chemical studies on tobacco smoke. III. Primary and secondary nitroalkanes in cigarette smoke; Beitr. Tabakforsch. 4 (1968) 124-134.

23. Hoffmann, D. and G. Rathkamp: Quantitative analysis of chlorinated hydrocarbon insecticides in tobacco and cigarette smoke; CORESTA Mtg., Stockholm, Sweden (1968); Chemical studies on tobacco smoke. V. Quantitative determination of chlorinated hydrocarbon insecticides in cigarette tobacco and its smoke; Beitr. Tabakforsch. 4 (1968) 201-214.

24. Brunnemann, K.D. and D. Hoffmann: On the $\mathrm{pH}$ of tobacco smoke; $26^{\text {th }}$ Tobacco Chemists' Research Conference [Joint Conference with CORESTA], Program Booklet and Abstracts, Vol. 26, Paper No. 11, 1972, pp. 16-17; [Chemical Studies on Tobacco Smoke. XXV.] The $\mathrm{pH}$ of tobacco smoke; Food Cosmet. Toxicol. 12 (1974) 115-124

25. Hoffmann, D. and E.L. Wynder: [A study of tobacco carcinogenesis. XXXVII] Chemical constituents and bioactivity of tobacco smoke; in: Tobacco: A major health hazard, edited by D.G. Zardidze and R. Peto, IARC, Lyon, France, IARC Sci. Publ. No. 74 (1986) 145-165.

Hoffmann, D. and S.S. Hecht: Advances in tobacco carcinogenesis; in: Chemical carcinogenesis and mutagenesis. I, edited by C.S. Cooper and P. Grover, Springer-Verlag, London, U.K., 1990, Chapter 3, pp. 63-102.

Hoffmann, D., A. Rivenson, F.L. Chung, and E.L. Wynder: Potential inhibitors of tobacco carcinogenesis; in: Tobacco smoking and nutrition: Influence of nutrition on tobaccoassociated health risks, edited by J.N. Diana and W.A. Prior, Ann. N.Y. Acad. Sci. 686 (1993) 140-160.

Hoffmann, D. and I. Hoffmann: [Chemical studies on tobacco smoke. C] The changing cigarette: 1950-1995; J. Toxicol. Environ. Hlth. 50 (1997) 307-364.

Hoffmann, D. and I. Hoffmann: Tobacco smoke components. Letter to the Editor; Beitr. Tabakforsch. Int. 18 (1998) 49-52. Hoffmann, D. and I. Hoffmann: The changing cigarette: Chemical studies and bioassays; in: Risks associated with cigarettes with low machine-measured yields of tar and nicotine, NCI smoking and tobacco control, Monograph 13, edited by D.M. Burns and N.L. Benowitz, United States Department of Health and Human Services, Bethesda MD, Chapter 5 (2001) 159-191.

Hoffmann, D., I. Hoffmann, and K. El-Bayoumy: The less harmful cigarette: A controversial issue. A tribute to Ernst L. Wynder; Chem. Res. Toxicol. 14 (2001) 767-790.
26. Closing Quotes Department: Dietrich Hoffmann: Author of the list; Tobacco Reporter (July 2002) pp. 70-72.

27. Cashmore, M.: Alternative smoking regimes: Hoffmann analyte formation and prediction as a consequence of changing smoking regimes and filter vent blocking; $56^{\text {th }}$ Tobacco Science Research Conference, Program Booklet and Abstracts, Vol. 56, Paper No. 29, 2002, pp. 35-36.

28. Dimandia, J.-M.D., S.B. Stanfill, and F.C. Glisson: Analysis of Hoffmann list compounds by comprehensive two-dimensional gas chromatography/time-of-flight mass spectrometry; $57^{\text {th }}$ Tobacco Science Research Conference, Program Booklet and Abstracts, Vol. 57, Paper No. 14, 2003, pp. 25-26.

Volgger, D., I. Rohregger, V. Unterholzner, and A. Zemann: Influence of cigarette paper properties on the formation of Hoffmann type analytes in smoke; $57^{\text {th }}$ Tobacco Science Research Conference, Program Booklet and Abstracts, Vol. 57, Paper No. 30, 2003, pp. 36-37.

Chang, Y.P., P.X. Chen, F.K. St. Charles, and S.C. Moldoveanu: Influence of tip ventilation on Hoffmann analyte deliveries; $57^{\text {th }}$ Tobacco Science Research Conference, Program Booklet and Abstracts, Vol. 57, Paper No. 44, 2003, pp. 45-46.

Warren, N.D.: The Hoffmann analyte to 'tar' ratio paradox; $57^{\text {th }}$ Tobacco Science Research Conference, Program Booklet and Abstracts, Vol. 57, Paper No. 46, 2003, p. 47.

Ellisor, T.A., J.-Z. Dong, and S.C. Moldoveanu: Variation in the level of Hoffmann analytes for mainstream cigarette smoke when a large volume of air passes through the collection device; $57^{\text {th }}$ Tobacco Science Research Conference, Program Booklet and Abstracts, Vol. 57, Paper No. 47, 2003, pp. 47-48.

Warren, N.D.: Prediction of mainstream cigarette smoke Hoffmann analyte yields by statistical modeling; $57^{\text {th }}$ Tobacco Science Research Conference, Program Booklet and Abstracts, Vol. 57, Paper No. 50, 2003, p. 50.

29. Loureau, J.-M., C. LeMoigne, L. LeBec, G. LeBourvellec, J.P. Biesse, G. Clarisse, B. Vidal, and B. Duméry: Hoffmann analytes: Influence of cigarette paper and filter ventilation; $58^{\text {th }}$ Tobacco Science Research Conference, Program Booklet and Abstracts, Vol. 58, Paper No. 70, 2004, p. 65.

30. Baker, R.R., J.R. Pereira da Silva, and G. Smith: The effect of tobacco ingredients on smoke chemistry. Part II: Casing ingredients; Food Chem. Toxicol. 42S (2004) 39S-52S: see p. 48. Table 10 heading: Significant smoke "Hoffmann analyte" increases . . . ; Baker, R.R., E.D. Massey, and G. Smith: An overview of the effects of tobacco ingredients on smoke chemistry and toxicity; Food Chem. Toxicol. $42 \mathrm{~S}$ (2004) 53S-83S: see p. S69, Table 3 heading: Pyrolysis products from tobacco ingredients that are included in the "Hoffmann lists" of smoke components; S70, Table 4 heading: Effect of ingredients in test cigarettes on smoke yields for those ingredients giving pyrolysis yields of "Hoffmann analytes" above the 'daily threshold limit'. 